\title{
Hydrodynamic and Mass Transfer Study in a Mechanically Stirred Hybrid Airlift Bioreactor Based on Impeller Type
}

\author{
Sérgio S. de Jesus, Aline Santana, and Rubens Maciel Filho
}

\begin{abstract}
The analysis of the influence by the impeller type in a stirred hybrid airlift bioreactor was performed in relation to the gas holdup, and mass transfer. The comparative study was performed using three-bladed marine and Lightnin A310 (axial flow impellers), and six-bladed Rusthon turbine and six-bladed Smith turbine (radial flow impellers). The experiments were conducted using distilled water at $25^{\circ} \mathrm{C}$ and a constant rotation velocity of $800 \mathrm{rpm}$, as well as in the absence of agitation (airlift mode); the superficial gas velocity varied from 0.0157 to $0.0262 \mathrm{~ms}^{-1}$. The gas holdup and oxygen transfer coefficient was higher with the use of radial impellers; however, the mechanical power input required while using radial impellers is $\mathbf{7 3 0 - 1 4 0 0 \%}$ higher than with axial impellers.
\end{abstract}

Index Terms-Axial Impeller, hydrodynamics, mass transfer, radial impeller, stirred airlift bioreactor.

\section{INTRODUCTION}

The increasing industrial use of airlift bioreactors has aroused interest in research aimed at the improvement of this technology. Airlift bioreactors are devices characterized by the absence of mechanical agitation, and by the large height to diameter ratio, which contribute to their low cost of both construction and operation, in addition to presenting fewer problems in relation to the coalescence of bubbles. Furthermore, these reactors present a main disadvantage in the low gas-liquid mass transfer rates, when employing non-Newtonian highly viscous mediums; thus, compromising its performance [1]-[3], in addition to problems related to the insufficient homogenization of the cell cultures when applied on a pre- or industrial scale, being unsuitable for high density biomass cellular concentrations higher than $30 \mathrm{~g}$ dw. $\mathrm{L}^{-1}$; since the mixture low efficiency can lead to limitations in the homogenization of the medium, and in the oxygen transfer [4]. Aerated mechanically stirred tank bioreactors are widely used in industrial settings. They are highly effective for mixing and homogenizing cell suspensions, presenting little formation of large cell aggregates, in addition to allowing easy control of the variables. However, the power consumption is relatively high, besides forming a much higher level of foam than the airlift bioreactor; another critical problem relates to high shear rates caused by the agitation [5]. Mechanically stirred airlift bioreactors are a viable alternative, for presenting some characteristics from both the traditional airlift reactors, and the aerated mechanically stirred tanks. Mechanically stirred hybrid airlift bioreactors have been described in the literature

Manuscript received September 5, 2013; revised November 4, 2013

S. S. de Jesus, A. Santana and R. Maciel Filho are with the School of Chemical Engineering, University of Campinas, Campinas, CP 6066 Brazil (tel.: 55-19-3521-3958; fax: 55-19-3521-3965; e-mail: ssjesus@ gmail.com).
[3], [6], [7], with the objective of improving the process, by increasing the mass transfer from the gas to the liquid phases. Bang et al., [6] proposed a new type of mechanically stirred airlift reactor, in which the agitator is located at the bottom of the reaction vessel, centered on the riser. According to these authors, the volumetric coefficient mass transfer increased up to four times, compared to a standard airlift reactor; this increase is due primarily to the bubbles collapse caused by the impeller, which also is directly related to the increase of the gas holdup. Pollard et al., [7] by using an impeller close to the bottom of the draft tube of an airlift bioreactor, were able to increase by $45 \%$ the productivity of the erythromycin antibiotic, when compared with a standard airlift bioreactor. Chisti and Jauregui-Haza [3] compared the mixture and oxygen transfer in a standard airlift bioreactor with two mechanical agitators; the first located near the center and another at the end of the draft tube. According to these authors, the use of axial flow impeller in the downcomer increased circulation of the liquid, the mixture, and the gas-liquid transfer, when compared to a standard airlift. However, these authors observed a significant increase in energy consumption. The effects from the type of impeller on the hydrodynamics, and the gas-liquid mass transfer in hybrid airlift bioreactors, require more studies. The impact of the type of impeller can be directly related to the efficiency and the yield by the process. Many studies compared the effectiveness of various types of impellers, in relation to volumetric oxygen transfer coefficient $\left(k_{L} a\right)$, and the gas holdup in aerated mechanically stirred bioreactors. Pinelli et al., [8] used three impellers (Rushton turbine, Lightnin A310 and A315), concluding that the axial impellers produce higher values of gas holdup; however, its efficiency in relation to the mass transfer was not confirmed. Other authors compared the effectiveness, and the configuration of multiple impellers with the $k_{L} a$ data.

Comparative studies using Rushton turbine impellers demonstrated a lower $k_{L} a$ values than Hollow blade turbine [9].

Other studies report that the use of Prochem MaxFlo T axial flow impellers showed $k_{L} a$ values $30 \%$ lower than the Rushton turbine impeller and the Narcissus impellers also showed higher $k_{L} a$ in relation to the Rushton turbine impeller [10].

This work verified the performance of a mechanically stirred hybrid airlift bioreactor in relation to the gas holdup and the gas-liquid oxygen transfer, in function of the type of impeller used. For the comparative studies were used: three-bladed marine (BM); Lightnin A310 axial impellers; six-bladed Rusthon turbine (RT), and six-bladed Smith turbine (CD6) radial impellers, with the same geometrical similarities. 


\section{MATERIAL AND METHODS}

\section{A. Bioreactor and Fluid}

Measurements were taken in a concentric draft-tube stirred airlift bioreactor (Fig. 1). The bioreactor vessel had $0.12 \mathrm{~m}$ in diameter and overall height of $0.40 \mathrm{~m}$. The draft-tube, with $0.09 \mathrm{~m}$ in internal diameter and $0.23 \mathrm{~m}$ tall, was located 0.05 $\mathrm{m}$ above the bottom of the tank. Air was sparged in the internal zone through a $0.05 \mathrm{~m}$ porous plate, with 90 holes of $0.001 \mathrm{~m}$ in diameter, and $0.003 \mathrm{~m}$ equidistant, located at the bottom of the bioreactor and concentric to the region comprised by the riser. The agitation process is held on the lower part of the bioreactor, which is centered on the gas sparger, and the region comprising the riser. The agitation was performed using either an axial impeller (three-bladed marine or Lightnin A310), or a radial (six-bladed Rusthon turbine or six-bladed Smith turbine), with the same geometrical similarities, and a diameter of $40 \mathrm{~mm}$ (Fig. 2). To avoid the formation of vortex, four baffles were added above the draft-tube. A dissolved oxygen electrode (O2-sensor InPro6800/12/220 Mettler Toledo, Switzerland), and $\mathrm{pH}$ probe (405-DPAS-SC-K8S/225 Mettler Toledo, Switzerland) were positioned at the centerline of the vessel, and $0.15 \mathrm{~m}$ above its bottom.

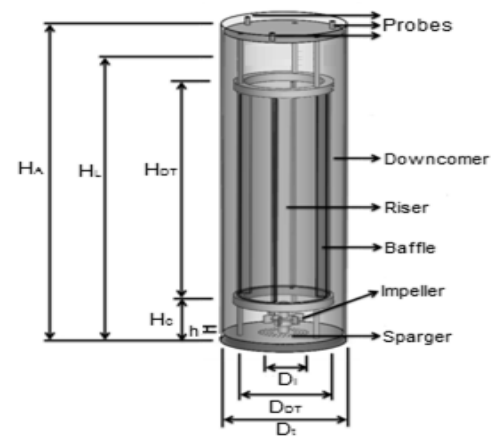

$\mathrm{H}_{\mathrm{A}}=0.40 \mathrm{~m}$ $\mathrm{H}_{\mathrm{L}}=0.33 \mathrm{~m}$ $\mathrm{H}_{\circ \mathrm{r}}=0.23 \mathrm{~m}$ $\mathrm{H}_{\mathrm{o}}=0.05 \mathrm{~m}$ $\mathrm{h}=0.003 \mathrm{~m}$ $\mathrm{D}_{1}=0.04 \mathrm{~m}$ Dor $=0.09 \mathrm{~m}$ $\mathrm{D}:=0.12 \mathrm{~m}$

Fig. 1. The schematic diagram of experimental bioreactor system.

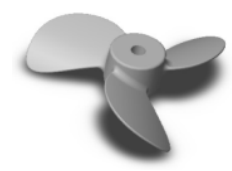

(a)

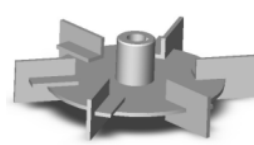

(c)

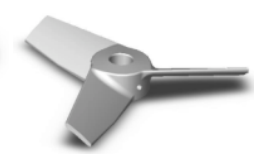

(b)

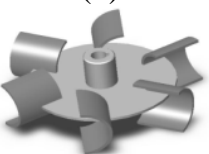

(d)
Fig. 2. The axial and radial impellers used in the experiments. (a) three-bladed marine (BM), (b) Lightnin A310 (A310), (c) six-bladed Rusthon turbine (RT), (d) six-bladed Smith turbine (CD6).

The reactor was sparged with either oxygen, or nitrogen. Distilled water was used as fluid model. The working volume of the bioreactor was of $3.2 \mathrm{~L}$. The superficial oxygen velocity in the riser $\left(U_{G R}\right)$ ranged from 0.0157 to 0.0262 $\mathrm{m} . \mathrm{s}^{-1}$.The agitation velocity was of $800 \mathrm{rpm}$. All experimental runs were carried out under normal atmospheric pressure, and temperature of $20^{\circ} \mathrm{C}$.

\section{B. Gas Holdup}

The total gas holdup $\left(\varepsilon_{G}\right)$ was measured by the volume expansion method as follows [1]:

$$
\varepsilon_{G}=\frac{h_{D}-h_{L}}{h_{D}}
$$

where $h_{D}$ is the height of gas-liquid dispersion, and $h_{L}$ is the height of gas free liquid.

\section{Volumetric Oxygen Transfer Coefficient}

The volumetric oxygen transfer coefficient $\left(k_{L} a\right)$ was measured using the dynamic gassing-in method [11]. For each test, the fluid was purged by bubbling nitrogen until reaching a dissolved oxygen concentration with less than $5 \%$ of air saturation. Later, the nitrogen flow was suspended, allowing the outflow of its bubbles, and establishing the airflow to the required condition. The increase in dissolved oxygen concentration was followed with time, until the fluid became nearly saturated with oxygen $(>90 \%)$. The $k_{L} a$ was calculated as the slope of the linear equation:

$$
-\ln (1-E)=k_{L} a\left(t-t_{0}\right)
$$

where $E$, is the fractional approach to equilibrium, and can be estimated by [1]:

$$
E=\frac{C-C_{0}}{C^{*}-C_{0}}
$$

where $C^{*}$ is the dissolved oxygen saturation concentration, $C_{0}$ is the dissolved oxygen initial concentration at time $t_{0}$ when a hydrodynamic steady-state has been reestablished ( $\leq 60 \mathrm{~s})$ upon the beginning of aeration, and $C$ is the dissolved oxygen concentration at any time $t$.

\section{Bubble Size}

The diameter of the bubbles for the studied conditions, were calculated from $k_{L} a$ experimental data, and $\varepsilon_{G}$, according to the equation [12]:

$$
d_{B}=\left(\frac{2.776 D_{L}}{\pi\left(1-\varepsilon_{G}\right) \psi^{2}}\right)^{2 / 5} \cdot\left(\frac{g \Delta \rho}{\rho_{L}}\right)^{1 / 5}
$$

where $D_{L}$ is the oxygen diffusion coefficient in the liquid, $\Delta \rho$ is the difference between the densities of the liquid and gas, $\rho_{L}$ is the liquid density, $g$ is the gravity acceleration, and $\psi$ is the proposed experimental relation given by [1]:

$$
\psi=\frac{k_{L} a\left(1-\varepsilon_{G}\right)}{6 \varepsilon_{G}}
$$

The power input due to mechanical agitation was calculated using the power number $\left(N_{p}\right)$, versus the impeller Reynolds number $(R e)$ [3].

$$
\begin{gathered}
P_{M}=N_{p} N^{3} d_{i}^{5} \rho_{L} \\
\operatorname{Re}=\frac{d_{i}^{2} N \rho_{L}}{\mu}
\end{gathered}
$$

The power number has been corrected according to the expression [13]: 


$$
f_{C}=\sqrt{\frac{\left(D_{t} / D_{i}\right)^{*}\left(H_{L} / D_{i}\right)^{*}}{\left(D_{t} / D_{i}\right)\left(H_{L} / D_{i}\right)}}
$$

where $f_{C}$ is the correction factor, * identifies the distinct geometric relations from the standard system.

\section{RESULTS AND DISCUSSIONS}

\section{A. Gas Holdup}

Fig. 3 shows the evolution of gas holdup in the water-air system as a function of the superficial gas velocity for the different types of impellers at a constant speed of rotation 800 $\mathrm{rpm}$, and in the absence of agitation (traditional airlift). The presence of agitation favored the increase of gas holdup, especially when using radial impellers. The experiments performed with radial impellers provided very similar results, in which there was an increase in function of the superficial gas velocity. However, when the experiments were performed with axial impellers, there was a very small increase in gas holdup, compared to experiments performed in the absence of agitation, especially when using a BM impeller. Studies performed with mechanically stirred tank reactors, showed that the RT impellers had higher gas holdup that the A315 [10], [14]. The gas holdup reliance on the superficial gas velocity was correlated according to the equation proposed by Chisti and Moo-Young [15]. Equations were given by:

$$
\begin{gathered}
\varepsilon_{G}=81.35 U_{G R}^{2.20 \pm 0.25}\left(R^{2}=0.991\right) \text { Airlift } \\
\varepsilon_{G}=35.08 U_{G R}^{1.95 \pm 0.29}\left(R^{2}=0.982\right) \mathrm{A} 310 \\
\varepsilon_{G}=84.90 U_{G R}^{2.20 \pm 0.32}\left(R^{2}=0.981\right) \mathrm{BM} \\
\varepsilon_{G}=5.87 U_{G R}^{1.30 \pm 0.27}\left(R^{2}=0.975\right) \mathrm{RT} \\
\varepsilon_{G}=7.24 U_{G R}^{1.37 \pm 0.16}\left(R^{2}=0.993\right) \mathrm{CD} 6
\end{gathered}
$$

The proposed equations allowed the observation that the exponent from the superficial gas velocity for the axial impellers, and without agitation (airlift) was practically the same within the error limits; the same was observed with the radial impellers, in this case the exponent of superficial velocity is lower than the exponent from the axial impellers.

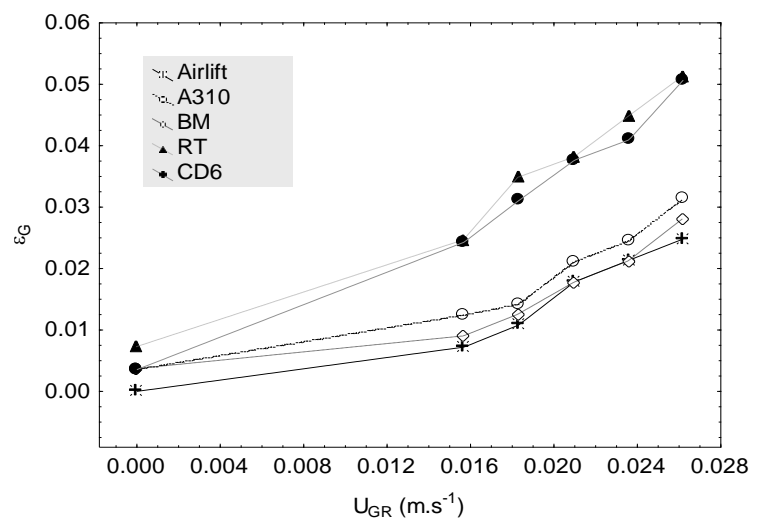

Fig. 3. The evolution of gas holdup as a function of the superficial gas velocity for the different types of impellers at a constant velocity of rotation of $800 \mathrm{rpm}$, and in the absence of agitation.

\section{B. Volumetric Oxygen Transfer Coefficient}

The volumetric oxygen transfer coefficient $\left(k_{L} a\right)$ is the key parameter for the scale-up design of a bioreactor. The oxygen supply in liquid form for cellular consumption is closely linked to the gas retention capacity in the culture medium, and the diameter of the bubbles formed inside the bioreactor. Fig. 4 shows the evolution of the volumetric mass transfer coefficient in function of the superficial gas velocity for all the impellers used at a constant rotation of $800 \mathrm{rpm}$, and in the absence of agitation. The presence of agitation in the bioreactor contributed, in all cases, to the $k_{L} a$ increase; however, when the radial impellers were used, there was an increase of $50 \%$ over the airlift mode and, $30-40 \%$ in relation to the axial impellers. It was also noticed that by increasing the superficial gas velocity, very close values of $k_{L} a$ were obtained for the two types of radial impellers used. Comparative studies with RT and A315 impellers in cultures of Streptomyces in a stirred bioreactor revealed that the $k_{L} a$ value increases by $50 \%$ with the use of RT impellers [16]. Other studies using a stirred reactor and water as the fluid model found that RT impellers present $k_{L} a$ values up to $40 \%$ higher, compared to the A315 impellers [14]; our studies confirmed that even with a stirred hybrid airlift bioreactor, the use of radial impeller favors the $k_{L} a$ increase. The reliance of $k_{L} a$ in function of the superficial gas velocity was expressed according to the following equations:

$$
\begin{aligned}
& k_{L} a=0.03 U_{G R}^{0.28 \pm 0.07}\left(\mathrm{R}^{2}=0.921\right) \text { Airlift } \\
& k_{L} a=0.13 U_{G R}^{0.59 \pm 0.10}\left(\mathrm{R}^{2}=0.963\right) \mathrm{A} 310 \\
& k_{L} a=0.10 U_{G R}^{0.55 \pm 0.09}\left(\mathrm{R}^{2}=0.962\right) \mathrm{BM} \\
& k_{L} a=0.13 U_{G R}^{0.56 \pm 0.06}\left(\mathrm{R}^{2}=0.984\right) \mathrm{RT} \\
& k_{L} a=0.24 U_{G R}^{0.62 \pm 0.15}\left(\mathrm{R}^{2}=0.971\right) \mathrm{CD} 6
\end{aligned}
$$

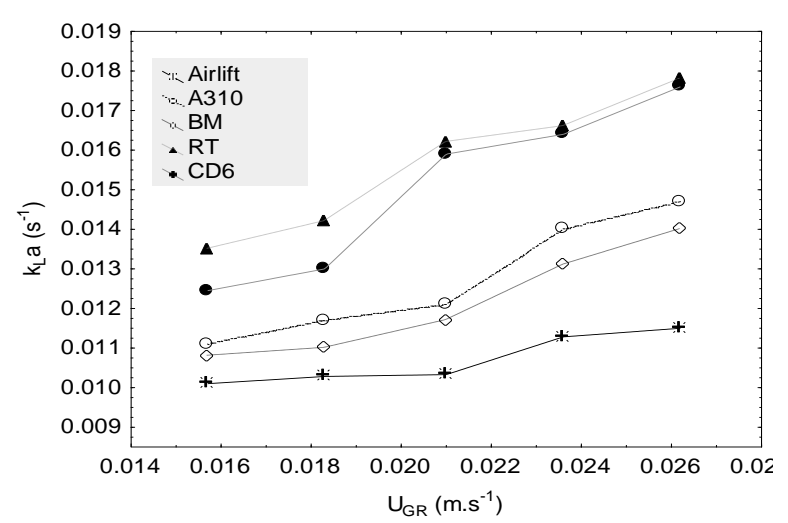

Fig. 4. The evolution of global oxygen mass transfer as a function of the superficial gas velocity for the different types of impellers at a constant velocity of rotation of $800 \mathrm{rpm}$, and in the absence of agitation.

\section{Bubble Size}

Fig. 5 shows the variation of bubble diameters as a function of the superficial gas velocity for all experiments performed with, and without agitation. The bubbles diameter increased with the superficial gas velocity, with the larger diameters being obtained with the radial impellers; Fig. 5 shows that the smaller diameter bubbles are formed when the bioreactor was operated as airlift, or when axial impellers 
were employed. The increase in diameter is directly related to the coalescence of bubbles within the column from the bioreactor. With the increase in the superficial gas velocity there is a proportional increase in the bubbles diameter caused by the collision between two or more bubbles; thus, forming bubbles with larger diameter. Another explanation for the increased diameter of the bubble is related to its ascent within the column, the higher it rises, the lower is the hydrostatic pressure of the liquid column above it, which can increase the diameter of the bubbles due to a lower resistance. However, this effect would be predominant on an analysis of coalescence as a function of the column height, and thus, with little significance. The presence of the agitation can be considered as the largest factor in the coalescence between bubbles, as agitation tends to accelerate the bubbles assent in the bioreactor column, and to increase the shock between them causing agglutination.

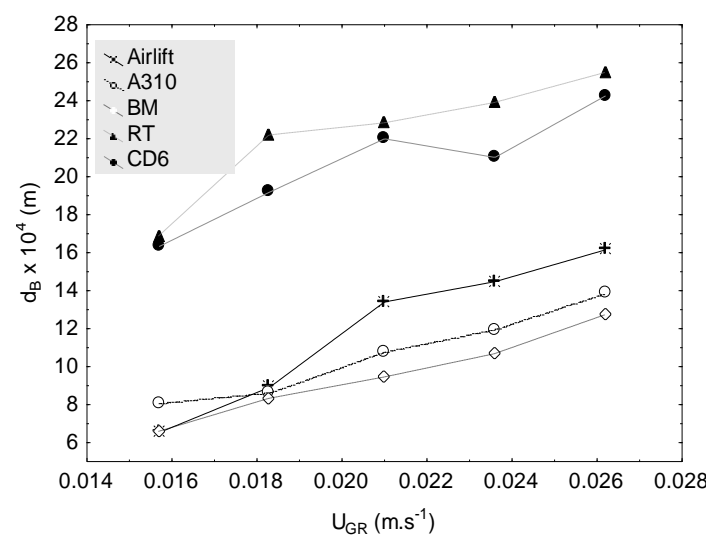

Fig. 5. The evolution of the bubbles diameters as a function of the superficial gas velocity for the different types of impellers at a constant velocity of rotation of $800 \mathrm{rpm}$, and in the absence of agitation.

Although the results have shown that the use of radial impellers in the agitation system of the airlift bioreactor favors performance in relation to gas hold-up and mass transfer. The energy consumption can be regarded as a limiting factor for the choice of impeller; Fig. 6 shows that the mechanical power required for the agitation in radial impellers ranges from 730 to $1400 \%$ in relation to the axial impellers. The choice of impeller is closely related to the cost/benefit ratio, in which the operating conditions will have as answer, the product yield; in this case whether the product has high added value, and the process is carried out, for example, with aerobic microorganisms, and for its growth and product formation requires high concentrations of liquid oxygen; the use of stirred airlift bioreactors can be a viable choice, and the radial impeller may be the best alternative.

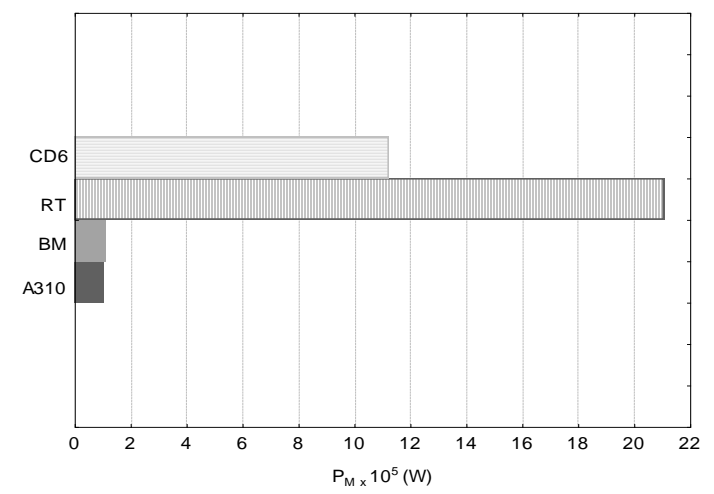

Fig. 6. Mechanical power input for the different types of impellers studied.

\section{CONCLUSION}

This study proved that the use of mechanical agitation in an airlift bioreactor enhances its performance. The axial impellers were not big contributors to the increases of gas holdup and $k_{L} a$, with the best results being achieved with the A310 model. In contrast, when the agitation was performed with radial impellers, there was a significant increase in gas holdup and $k_{L} a$; similar values were obtained for both the impellers studied. However, it should be noted that the choice of impeller or its use in an airlift bioreactor depends on the process and the desired product, since it was determined that the mechanical power required to agitate using radial impellers is $730-1400 \%$ higher than in axial impellers.

\section{ACKNOWLEDGMENT}

The authors wish to acknowledge the financial support provided by the State of São Paulo Research Foundation (FAPESP, processes $n^{\circ}$ 2008/57873-8, 2010/04903-7 and 2010/03764-3), and the National Council Scientific and Technological Development $\left(\mathrm{CNPq}\right.$, process $\mathrm{n}^{\circ}$ 150805/2009-8).

\section{REFERENCES}

[1] Y. Chisti, Airlift Bioreactors, 1st ed. New York, U.S.A.: Elsevier, 1989, pp. 345.

[2] S. Talvy, A. Cockx, and A. Liné, "Modeling of oxygen mass transfer in a gas-liquid airlift reactor," AIChE J., vol. 53, no. 2, pp. 316-326, Feb. 2007.

[3] Y. Chisti and U. J. Jauregui-Haza, "Oxygen transfer and mixing in mechanically agitated airlift bioreactors," Biochem Eng J., vol. 10, pp. 143-153, Mar. 2002.

[4] L. Luo, Y. Yan, Y. Xu, P. Xie, J. Sun, W. Guo and J. Yuan "Study of pressure fluctuations in an internal loop airlift bioreactor," Can. J. Chem. Eng., vol.91, no. 2, pp. 212-222, Feb. 2013.

[5] T. Yusaf, "Experimental study of microorganism disruption using shear stress," Biochem. Eng. J., vol.79, pp. 7-14, Oct. 2013.

[6] W. Bang, I. Nikov, H. Delmas and A. Bascoul, "Gas-liquid mass transfer in a new three-phase stirred airlift reactor," J. Chem. Technol. Biotechnol., vol. 72, pp. 137-142, June 1998.

[7] D. J. Pollard, A. P. Ison, P. A. Shamlou and M. D. Lilly, "Reactor heterogeneity with Saccharopolyspora erythraea airlift fermentations," Biotechnol. Bioeng., vol. 58, no. 5, pp. 453-463, June 1998.

[8] D. Pinelli, M. Nocentini and F. Magelli, "Hold-up in low viscosity gas-liquid systems stirred with multiple impellers. Comparison of different agitador types and sets," Institution of Chemical Engineers Symposium Series, no. 136, pp. 81-88, 1994.

[9] X. Geng, Z. Gao and Y. Bao, "PIV study of flow in an tank with a Hollow blade turbine", Int. J. Chem. React. Eng., vol. 10, no. 1, pp. 1542-1580, Apr. 2012.

[10] T. Moucha, V. Linek, and E. Prokopová, "Gas hold-up, mixing time and gas-liquid volumetric mass transfer coefficient of various multiple-impeller configurations: Rushton turbine, pitched blade and techmix impeller and their combinations," Chem. Eng. Sci., vol. 58, no. 9, pp. 1839-1846, May 2003.

[11] F. Garcia-Ochoa and E. Gomez, "Bioreactor scale-up and oxygen transfer rate in microbial processes: An overview," Biotechnol. Adv., vol.27, no. 2, pp. 153-176, Apr. 2009.

[12] M. O. Cerri, J. C. Baldacin, A. J. G. Cruz, C. O. Hokka, and A. C. Badino, "Prediction of mean bubble size in pneumatic reactors," Biochem. Eng. J., vol. 53, no. 1, pp. 12-17, Dec. 2010.

[13] S. Aiba, A. E. Humphrey, and N. F. Millis, Biochemical Engineering, 2nd ed. New York, U.S.A.: Academic Press, 1973, pp. 434.

[14] R. Sardeing, J. Aubin, and C. Xuereb, "Gas-liquid mass transfer: a comparison of down- and up-pumping axial flow impellers with radial turbines", Trans IChemE, vol. 82, no.12, pp.1589-1596, Dec. 2004.

[15] Y. Chisti and M. Moo-Young, "Hydrodynamics and oxygen transfer in pneumatic bioreactor devices," Biotechnol. Bioeng., vol. 31, no. 5, pp. 487-494, Apr. 1988.

[16] B. H. Junker, M. Stanik, C. Barna, P. Salmon, and B. C. Buckland, "Influence of impeller type on mass transfer in fermentation vessels," Bioproc. Eng. vol. 19, no. 6, pp. 403-413, Dec. 1998. 


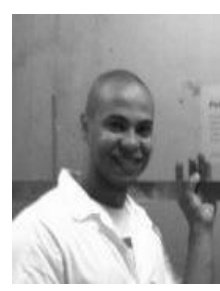

Sérgio Santos de Jesus was born at Rio de Janeiro. $\mathrm{He}$ has got her bachelor degree from Federal University of Rio de Janeiro, Rio de Janeiro, Brazil, on 1999. In 2002, he has got her master degree from University of Campinas, Campinas, Brazil. He got her Doctoral degree from Autonomous University of Barcelona, Barcelona, Spain in 2008. He joined the School of Chemical Engineering at University of Campinas as a post-doctoral fellow in 2011. His research interests are in the areas of biochemical engineering and transport phenomena.

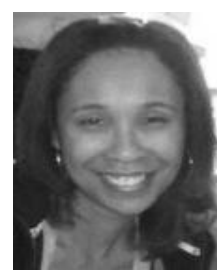

Aline Santana Scotelari de Souza was born at Rio de Janeiro. She has got her bachelor degree from Federal Rural University of Rio de Janeiro, Rio de Janeiro, Brazil, on 1999. She got her Doctoral degree from Polytechnic University of Catalonia, Barcelona, Spain in 2009. She joined the School of Chemical Engineering at University of Campinas as a post-doctoral fellow in 2011. His research interests are in the areas of supercritical fluids technology for clean biofuel production and thermodynamics.

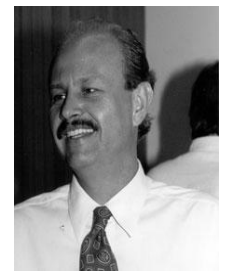

Rubens Maciel Filho was born at São Paulo. He has got bachelor degree from Federal University of São Carlos, Brazil, on 1981. In 1985, he has got her master from University of Campinas, Brazil. He got her Doctoral degree from University of Leeds, UK in 1989. Currently he is working as Professor of Chemical Engineering, University of Campinas and Coordinator of the Laboratory of Optimization, Design and Advanced Process Control (LOPCA) since 1989. He has published and presented 100 papers in International and National conferences and journals. The main research areas covers Modeling of Chemical and Biochemical Process: Computer Aided Design, operation and control and off/on line optimization, with special focus in Green Process Development and bio-refinery, specifically with bio-ethanol and byproducts from fermentation as feedstock. Consideration is also given for the use of $\mathrm{CO} 2$ and bio-ethanol as raw material for chemicals. He served as Head of Chem. Process Development, Director for Under Graduate Studies, Dean of Chemical Engineering School and Pro-Rector at University of Campinas. 